\begin{tabular}{l|l|l}
\hline \hline Vol. 24(3):255-261 & Ocean and Polar Research & September 2002 \\
\hline \hline
\end{tabular}

\title{
Article
}

\section{Distribution of Antarctic Sea Ice from Satellite Altimetry in the Weddell Sea: Preliminary Results}

\author{
Jeong Woo Kim*, Sungmin Hong', Jong-Sun Hwang ${ }^{3}$, Ho-Il Yoon ${ }^{2}$, \\ Bang Yong $\mathrm{Lee}^{2}$, and Yeadong $\mathrm{Kim}^{2}$ \\ 'Department of Earth Sciences and Research Inst. of Geoinformatics \& Geophysics \\ Sejong University, 98 Gunja-dong, Gwangjin-gu, Seoul 143-747, Korea \\ ${ }^{2}$ Polar Sciences Laboratory, KORDI \\ Ansan P.O. Box 29, Seoul 425-600, Korea \\ ${ }^{3}$ Department of Earth System Sciences, Yonsei University \\ 134 Sincheon-dong, Seodaemun-gu, Seoul 120-749, Korea
}

\begin{abstract}
We investigated the distribution of sea ice using Topex/Poseidon (T/P) and ERS-1 radar altimeter data in the northwest Weddell Sea, Antarctica, between the area $45-75^{\circ} \mathrm{W}$ and $55-66^{\circ} \mathrm{S}$. Using the Geo_Bad_1 flag of the Merged GDR of the T/P, we classified the surface into ocean, land, and sea. Total 257 cycles of altimeter measurements between Oct. 1992 and Sep. 1999 (for nearly 2570 days) were used to analyze the distribution of the Antarctic sea ice. We then calculated the surface area of ice coverage using SUTM20 map projection to monitor the periodic variations. Each year, the maximum and minimum coverage of the sea ice were found in late August and February in the study area, respectively. We also studied the sea ice distribution using ERS-1 altimeter data between $45-75^{\circ} \mathrm{W}$ and $55-81.5^{\circ} \mathrm{S}$ to compare with the T/P. Using the Valid/Invalid flag of the Ocean Product, we analyzed the sea ice distribution between March and August of 1995, which showed very good coherence with the T/P measurements. Our preliminary results showed that the altimeter measurements can be effectively used to monitor the distribution of the sea ice in the polar region. However, the size of radar footprint, typically 2-6 km depending on the roughness of the sea surface, may be too big to monitor the sharp boundary between ice and water/ land. If more other altimeter mission data with dense coverage such as Geosat GM are analyzed together, this limitation can be significantly improved. If we also combine other microwave remote sensing data such as radiometer, and SSM/I, the result will be significantly enhanced.
\end{abstract}

Key words : sea ice, radar altimetry, Topex/Poseidon, ERS-1, Weddell Sea, Antarctica.

\section{Introduction}

In general, the polar and adjacent seas are seasonally covered with a thin, uneven sheet of sea ice formed by the freezing of sea surface water. The area of sea covered by this ice varies strongly with the season. During the peak coverage, in the austral spring of Antarctica, the sea ice extends into the mid-latitudes where its presence impacts human and all other living thing's activities. During the minimum coverage, however, in late austral summer and

*Corresponding author. E-mail : jwkim@sejong.ac.kr early fall, the ice is confined to the Antarctic margin (Jeffries 1998; Carsey et al. 1992).

Satellite is now becoming a promising platform for polar geophysical and oceanographical information. In particular, in the polar region, the spatial scales are vast, transportation is difficult and hazardous, operations are expensive, and the climate is hostile. Satellite instruments are thus natural tool for environmental observations, and numerous visible and infrared spaceborne systems have made, and will continue to make, valuable contributions to ice surveillance (Kim et al. 2001; Hong et al. 2000; Fu and Cazenave 2001; Massom 1991). To overcome these 


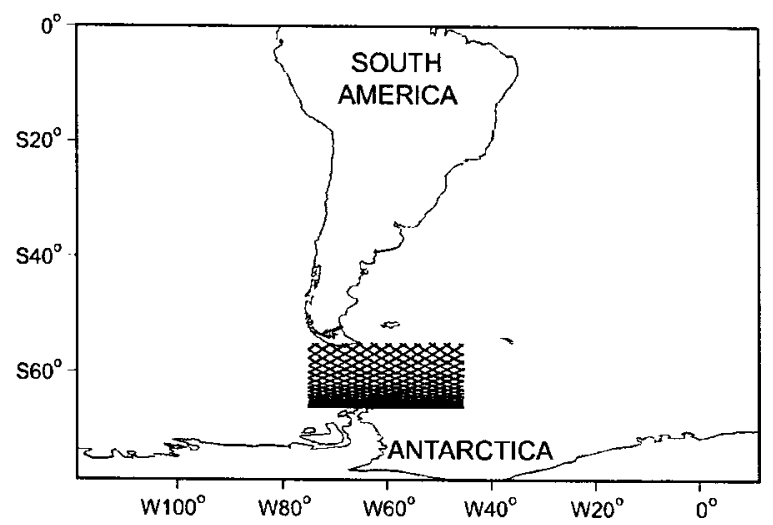

Fig. 1. Topex/Poseidon ground tracks of the study area $\left(45-75^{\circ} \mathrm{W}\right.$ and $\left.55-66^{\circ} \mathrm{S}\right)$ in the northwest Weddell Sea, Antarctica.

sensors' limitations to weather and light levels, microwave systems have been designed and flown since the 1970's.

In general, four microwave remote sensing techniques are used for sea ice study in the polar region; passive microwave imaging radiometer, SAR, radar scatterometer, and radar altimeter. In this study, we investigated the distributions of sea ice using Topex/Poseidon (T/P) radar altimeter data in the northwest Weddell Sea, Antarctica between the area $45-75^{\circ} \mathrm{W}$ and $55-66^{\circ} \mathrm{S}$ (Fig. 1). Although originally designed to study changes in ocean currents with atmospheric and climate patterns, the T/P altimeter data can also be used to monitor polar sea ice and ice sheet. Since the performance of radar altimeter over the ice surface differs significantly from the performance over oceans, various information of the ice sheet including elevation changes, mass balance, and seasonal variation of ice sheet extent can be obtained. Furthermore, its repeat coverage of 10 days is very useful to monitor the extent of sea ice to make a time-series of consistent data since its launch.

We also used ERS-1 altimeter data between $45-75^{\circ} \mathrm{W}$ and $55-81.5^{\circ} \mathrm{S}$ to compare the results with $\mathrm{T} / \mathrm{P}$ measurements. Using the Valid/Invalid flag of the Ocean Product (OPR), we mapped the sea ice distribution between March and August of 1995. Our preliminary results showed that the T/P and ERS-1 altimeter measurements, which had very good correlation with each other in the study area, can be effectively used to monitor the distribution of the sea ice.

\section{Theoretical background}

Satellite radar altimetry (SRA) is a non-imaging, active

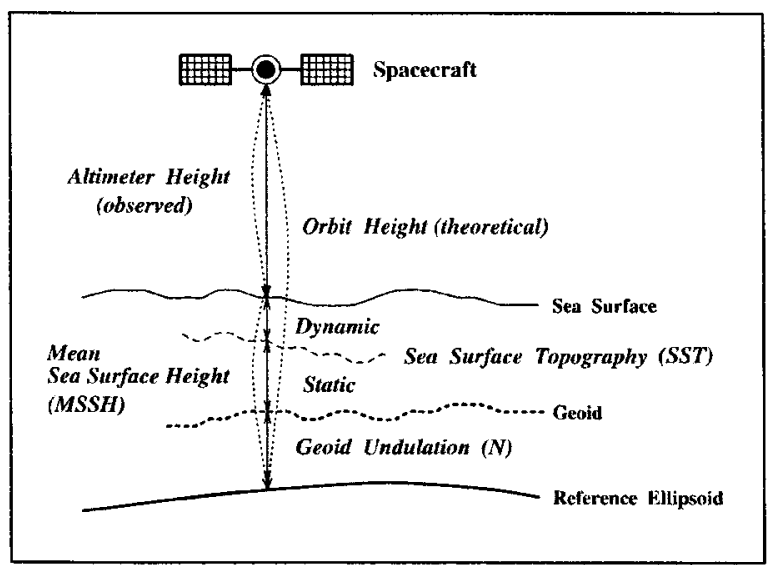

Fig. 2. Geometry of satellite radar altimetry.

remote sensing technique, using radar pulse (13.6 and 5.3 $\mathrm{GHz}$ for Topex/Poseidon mission). The spaceborne altimeter emits a radar pulse with a spherical wavefront that reflects from the Earth's surface and is received. If the two-way travel time is recorded, the distance between the satellite and sea surface can be obtained by subtracting the altimeter height from the orbit height as shown in Fig. 2.

Over the ice surfaces, the performance of the radar altimeters differs significantly from that over oceans due to the higher slopes of the ice surface, variations in the surface reflection and penetration of the radar signal in the snow surface, and general irregular surface geometry. The altimeter receives and filters the return signal, and the output signal from the filter is called waveform. This waveform has information on the surface characteristics (i.e., water, land, and ice).

Waveforms over sea ice and the ice sheet are very different from the typical ocean waveform as shown in Fig. 3. Over the ocean surfaces, the distribution of the heights of reflecting facets is (near) Gaussian, and the echo waveform has a characteristic shape that can be described analytically, as a function of the standard deviation of the distribution, which is closely related to the ocean wave height. On the other hand, an altimeter waveform over the ice surface where the typical return echo has unpredictable shape and can have a larger variability in surface elevation. Consequently, detailed information about the properties of ice surface can be obtained by examination of the waveforms ( $\mathrm{Fu}$ and Cazenave 2001; Carsey 1992). SRA thus can be used for various fields of polar sea ice study, such as seasonal and inter-annual variations of the ice sheet surface balance and elevation changes of ice sheet. 


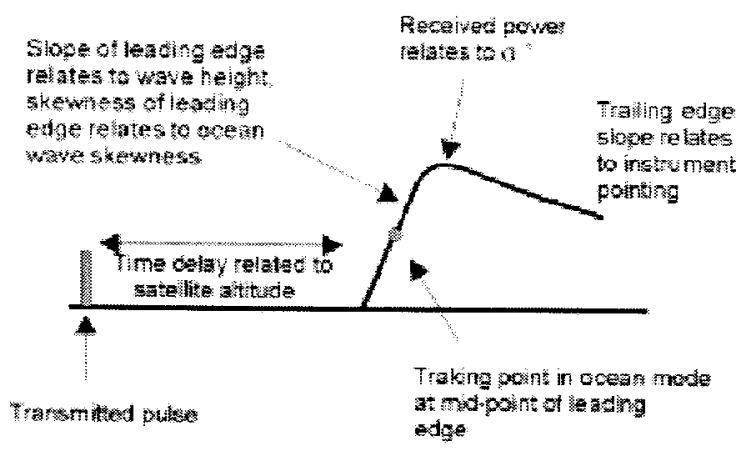

(a)

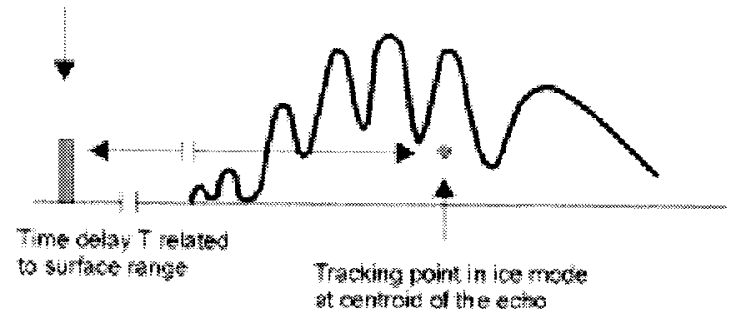

(a)

Fig. 3. Schematic profile of a returned echo form (a) ocean surface and (b) altimeter waveform over ice surface.

\section{Mission and data}

\section{Topex/Poseidon MGDR}

Topex/Poseidon (T/P) is jointly conducted by the US's NASA and the French's CNES for studying the global circulation from space. The mission uses the technique of satellite radar altimetry to make precise and accurate observations of sea level for several years (Benada 1997). T/P was launched into the Earth's orbit in Aug., 1992. From its orbit of $1,336 \mathrm{~km}$, the T/P measures sea level along the same path every 10 days using two altimeters developed by NASA and French CNES. The inclination of $\mathrm{T} / \mathrm{P}$ is $66.04^{\circ}$.

The Merged Geophysical Data Record (MGDR) of T/P provides the full mission data set with many data quality improvements brought about by the work of many scientists during the mission. It incorporates the improved orbits, new tide models, and some improved algorithm that have been developed also during the mission. The MGDR contains 123 fields of scientific records that are logically grouped, such as Time, Location, and Geophysical Quantity Groups. Among the Flags Group, the Geo_Bad_1 parameter is Ocean/Land/Ice flag, defined as set of flags
Table 1. Geo_bad_1 flag of the MGDR Topex/Poseidon altimeter data (modified from Beneda 1997).

\begin{tabular}{cll}
\hline Bits & \multicolumn{1}{c}{ Definition } & \multicolumn{1}{c}{ Value } \\
\hline 0 & Deep water flag & 0 - Deep water \\
& & 1 - Shallow water \\
1 & Land/water flag for the altimeter & 0 - Water \\
& & 1 - Land \\
2 & Land/water flag for the TMR & 0- Water \\
& & 1 - Land \\
3 & Ice surface as detected by the & 0 - No ice \\
& TMR & 1 - Ice \\
$4-7$ & Spares $(0)$ & \\
\hline
\end{tabular}

Table 2. Bits combinations of Geo_bad_1 flag of the MGDR Topex/Poseidon altimeter data.

\begin{tabular}{ccll}
\hline Binary No. & Decimal No. & \multicolumn{1}{c}{ Definition } & Surface \\
\hline 0000 & 0 & Deep water & WATER \\
0001 & 1 & Shallow water & \\
\hline 0010 & 2 & Water/Land/Deep & \\
0011 & 3 & Water/Land/Shallow & LAND or \\
0100 & 4 & Land/Water/Deep & WATER \\
0101 & 5 & Land/Water/Shallow & \\
\hline 0110 & 6 & Land/Land/Deep & LAND \\
0111 & 7 & Land/Land/Shallow & \\
\hline 1000 & 8 & Ice/Water/Water/Deep & \\
1001 & 9 & Ice/Water/Water/Shallow & \\
1010 & 10 & Ice/Water/Land/Deep & \\
1011 & 11 & Ice/Water/Land/Shallow & ICE \\
1100 & 12 & Ice/Land/Water/Deep & \\
1101 & 13 & Ice/Land/Water/Shallow & \\
1110 & 14 & Ice/Land/Land/Deep & \\
1111 & 15 & Ice/Land/Land/Shallow & \\
\hline
\end{tabular}

indicating ocean/land/ice states. Table 1 shows how Bits (0-7) are defined for the flag.

In Table 2, the 16 possible combinations of 8 Bits of the flag shown in Table 1 are described. We classified the surface based on these combinations. We assumed that the surface is entirely covered with ice (shaded boxes) if ice was detected in the footprint of the radar.

\section{ERS-1 OPR}

We also analyzed ERS-1 (First European Remote Sensing Satellite) OPR (Ocean Product) (CLS 1993) altimeter data between $45-75^{\circ} \mathrm{W}$ and $55-81.5^{\circ} \mathrm{S}$ to test the veracity by comparing the other spaceborne radar altimetry mission data. The ERS-1 OPR data are recorded on 9 CDs in binary format. Each CD contains multiple 111 byte 
records arranged by orbit days. Within each record, ten 0.1 -second altitude observations are used to determine the one second interval altitude. Times, locations, and correction terms are all given for the one-second observations.

The OPR Records are composed of two major parts; Header records, and measurements records. In this study we analyzed the second value of the Measurement Records, MCD, which stands for Measurement Confidence Data. The element and storage type of the MCD are Bitfield and $4 \mathrm{Bit}$, respectively, and this is the combination of the Flags from $1 \mathrm{~Hz}$ altimeter measurements (French Processing and Archiving Facility 1995). Valid/Invalid (V/I), Estimates, Operating Mode are the types of the Flag, and in this
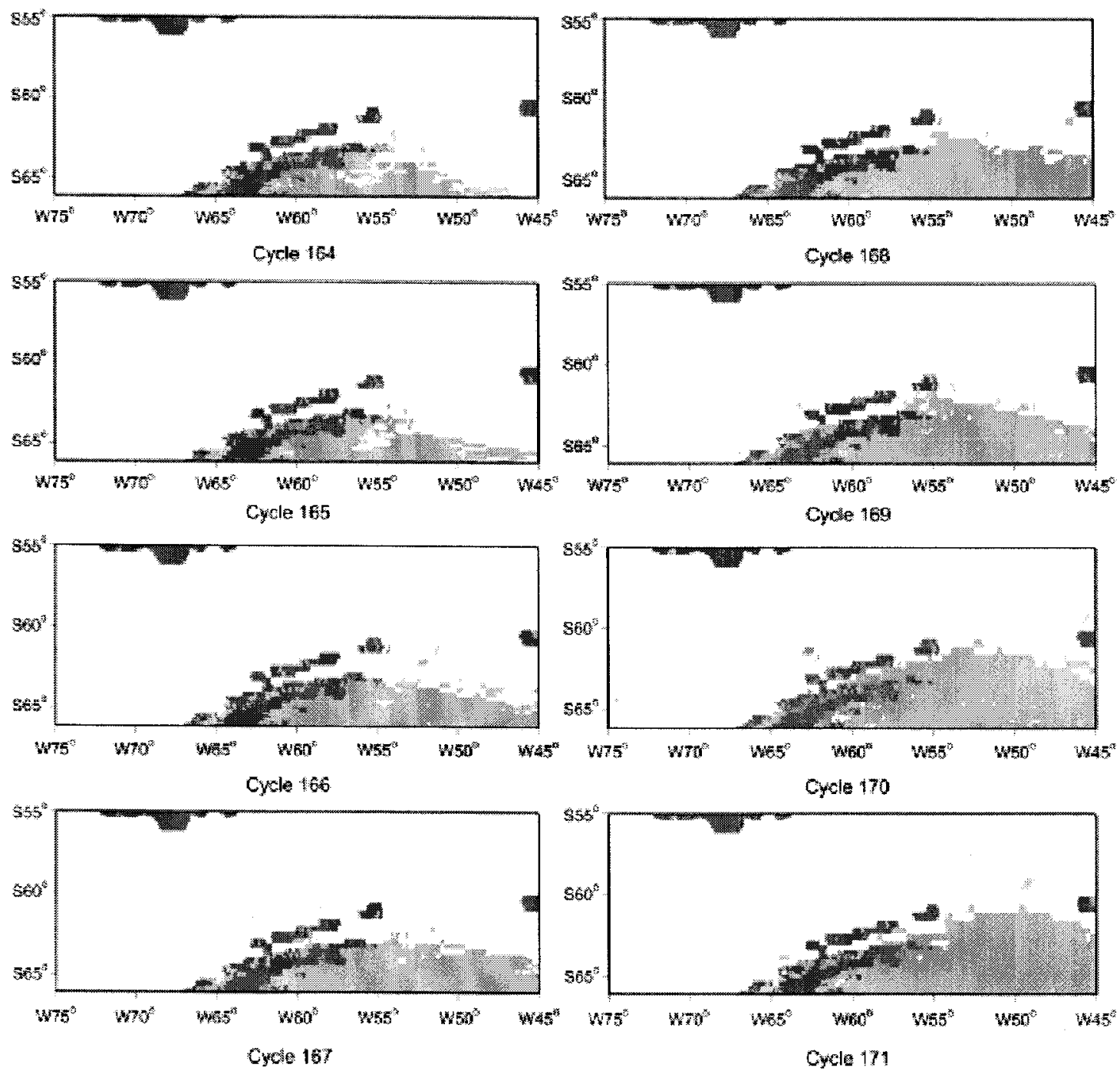

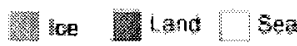

Fig. 4. Distributions of land, sea, and ice surfaces in the study area estimated from Topex/Poseidon MGDR Cycles 164-171. 
164 to 171 to test the veracity of our method to classify the ice surface in the study area. Since one cycle contains about 10 days of the measurements, total 80 days of measurements were analyzed. The first Cycle 164 contains the data from Feb. 25, 1997 and the last Cycle 171 contains the data until May 15, 1997.

For each cycle, the Geo_Bad_1 flag was investigated based on the combinations and the surface characteristics were selected. Fig. 4 shows the ice coverage for each cycle with measurement period. In the figure, white, gray, and dark gray colors indicate sea, ice, and land, respectively. It is easily found that the area of ice surface has been

Table 3. Combinations of Valid/Invalid flags of the ERS-1 OPR data.

\begin{tabular}{|c|c|c|c|}
\hline \multirow{2}{*}{$\begin{array}{l}\text { Bit } \\
\text { No. }\end{array}$} & \multirow{2}{*}{ Binary } & \multicolumn{2}{|r|}{ Mode } \\
\hline & & Flag & \\
\hline \multirow{2}{*}{ Bit 0} & 0 & Measurement & \multirow{2}{*}{ ValidInvalid } \\
\hline & 1 & Validity & \\
\hline \multirow{4}{*}{ Bits 1-3 } & 001 & \multirow{4}{*}{$\begin{array}{l}\text { Cause of } \\
\text { Invalidity }\end{array}$} & Acquisition Mode \\
\hline & 010 & & $\begin{array}{l}\text { Not Acquisition Mode, but over } \\
\text { Land }\end{array}$ \\
\hline & 011 & & $\begin{array}{l}\text { Not Acquisition Mode, but over } \\
\text { Land, but not ocean measurement }\end{array}$ \\
\hline & 100 & & $\begin{array}{l}\text { Other operating mode } \\
\text { (generally ice tracking mode) }\end{array}$ \\
\hline
\end{tabular}

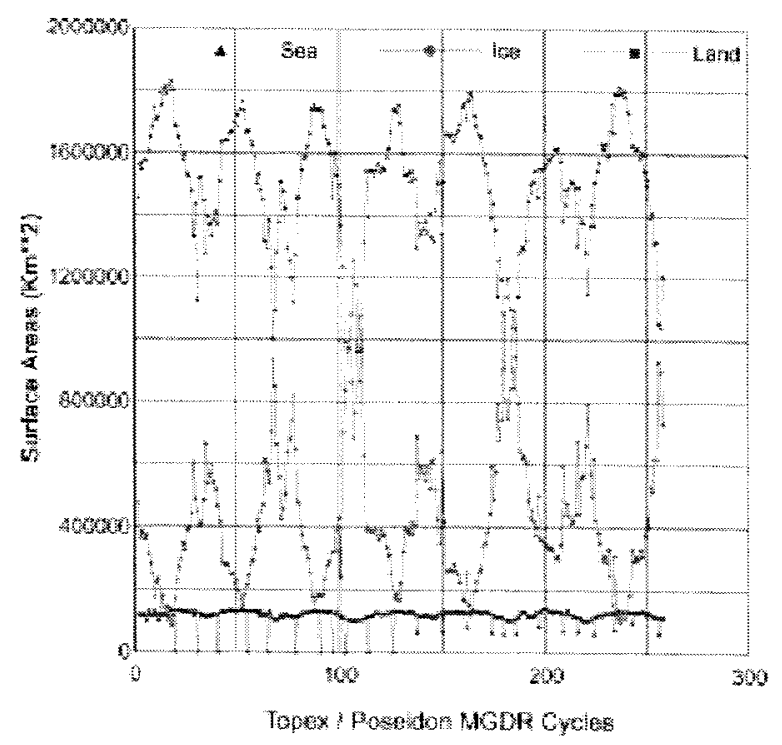

Fig. 5. Areas of altimetry-implied land, sea, and ice surfaces estimated from T/P measurements. Brown, blue, and red colors denote land, sea, and ice surfaces, respectively. increased to the north toward the austral winter. In the same manner, we analyzed the MGDR Cycles 2 to 257, which correspond to nearly 7 years of observations (Oct. 1992-Sep. 1999) that are not presented here.

To estimate the seasonal variations of surface areas for ice, we projected each cycle-map (2-257) into the SUTM20 and calculated the area of the ice. In Fig. 5, which shows the surface area of land, sea, and ice surfaces, the periodic variations of each surface are well shown. We then calculated the annual (upper) and the averaged annual (lower) surface areas of altimetry-implied
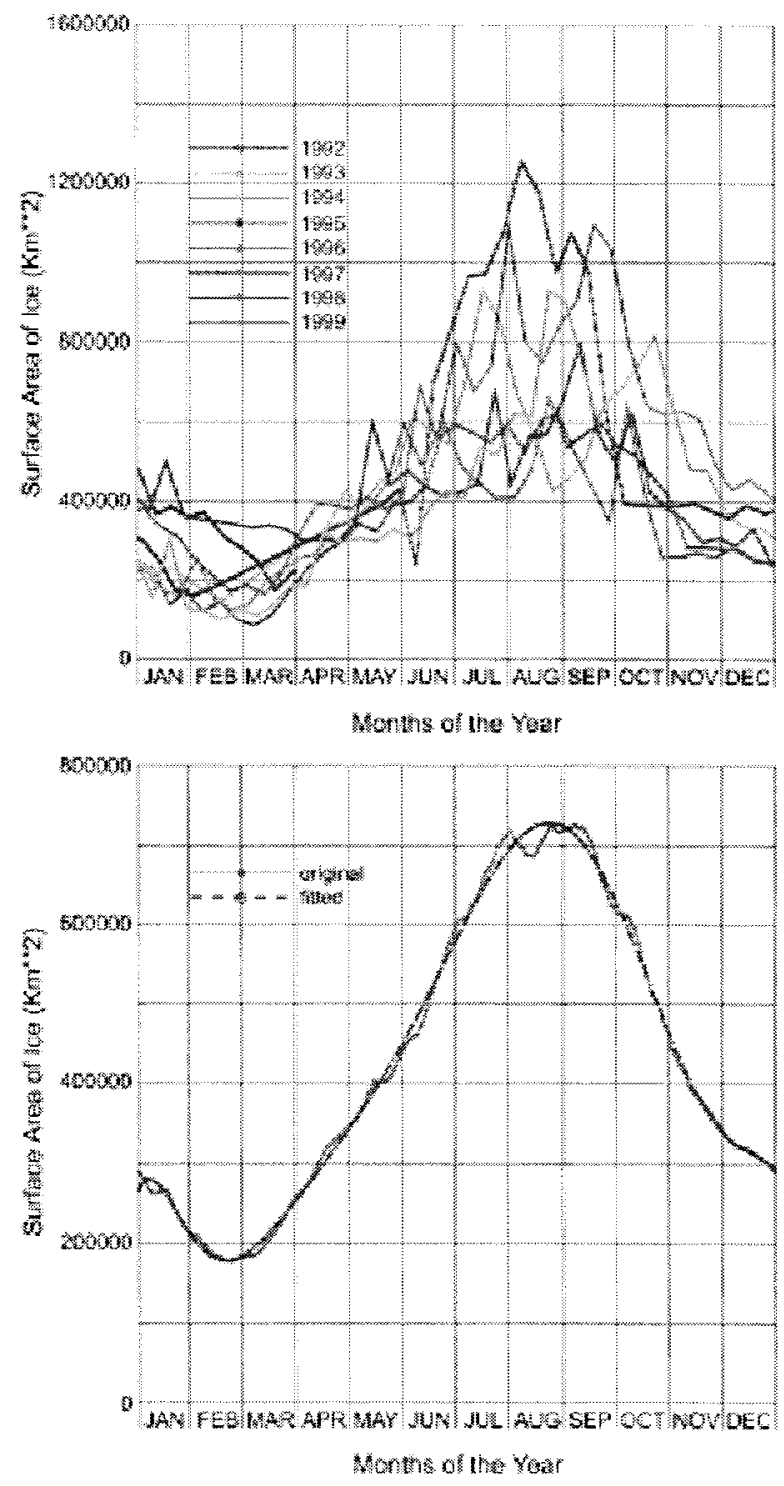

Fig. 6. Annual (upper) and averaged annual surface areas of altimetry-implied sea ice (lower) in the study area. 
sea ice in the study area that are shown in Fig. 6. In the lower panel of the figure, the broken and solid lines denote original and polynomially-fitted curves, respectively. Each year, the maximum and minimum coverage of the sea ice were found in late August and February, respectively.

\section{Comparison with ERS-1 OPR}

We also analyzed ERS-1 OPR between $45-75^{\circ} \mathrm{W}$ and $55-81.5^{\circ} \mathrm{S}$ to test the veracity by comparing the other spaceborne radar measurements. Using the Valid/Invalid flag of the OPR, in the similar manner used in the T/P processing, we mapped the sea ice distribution between March (Cycle 144) and August of 1995 (Cycle 148) as shown in Fig. 7. The ice-covered areas are shown as blank
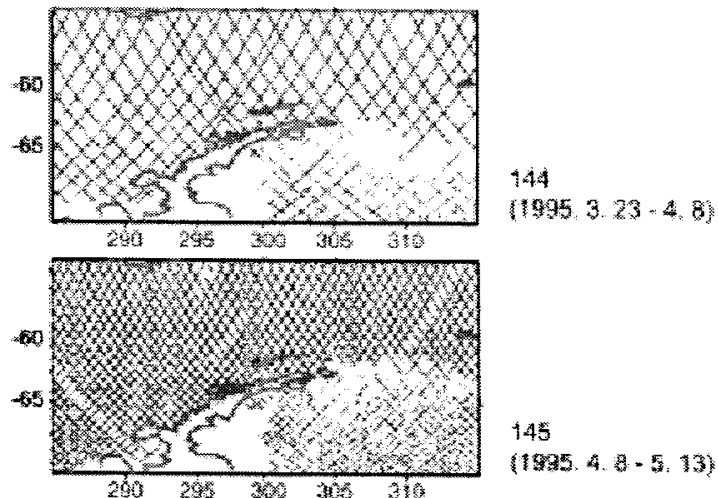

145

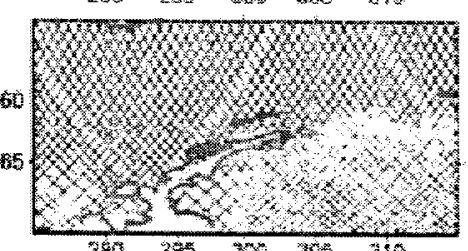

(1925. $4.9-5.3$

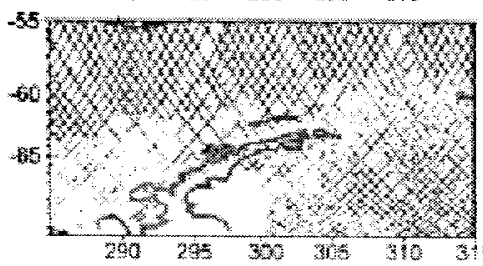

148

$(1995.5,13 \times 6.19$

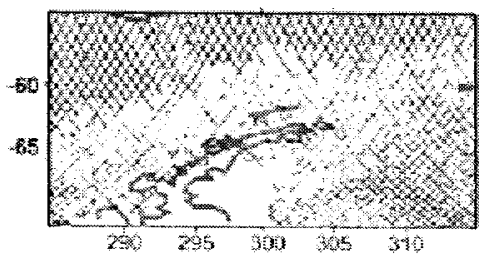

147

$(1925.19-7,22)$

148

(1225.7.22-3.26)

Fig. 7. Distribution of sea ice estimated from ERS-1 OPR Cycles 144-148. The areas which are not covered with the ERS-1 ground tracks are the northern edges of the sea ice. areas due to lack of data (i.e., ground tracks), and, hence, the northern edge of the sea ice in the figure is defined by a series of blank area. Here, the seasonal fluctuation of the sea ice was also detected.

We then compared the sea ice surface observed from $\mathrm{T} /$ $P$ and ERS- 1 measurements during the austral autumn of 1995. We selected Cycles 94, 95, 96 of T/P and Cycle 145 of ERS-1, which correspond to Apr. 2-May 2 and Apr. 8May 13, respectively. Fig. 8 shows the distribution of altimetry-implied sea ice. The upper panel is the result from $\mathrm{T} / \mathrm{P}$ and the lower panel is the result from ERS-1. For the ERS-1 data, the second panel of Fig. 7 (Cycle 145) was modified such that the remaining tracks over the ice surface were completely eliminated. It was found that the two results have good coherence in terms of the northern edge of the sea ice in the study area.

\section{Conclusions and discussions}

We investigated the distribution of sea ice using Topex Poseidon (T/P) and ERS-1 altimeter data in the northwest Weddell Sea, Antarctica. Using the Geo_Bad_1 flag of the $\mathrm{T} / \mathrm{P}$, we classified the surfaces into ocean, land, and sea ice based on the return waveforms. Total 257 cycles of altimeter measurements between Oct. 1992 and Sep. 1999 were analyzed to study the distribution of sea ice. We then calculated the surface area of ice coverage using SUTM20 map projection to quantify the periodic variations. Each year, the maximum and minimum coverages of sea ice

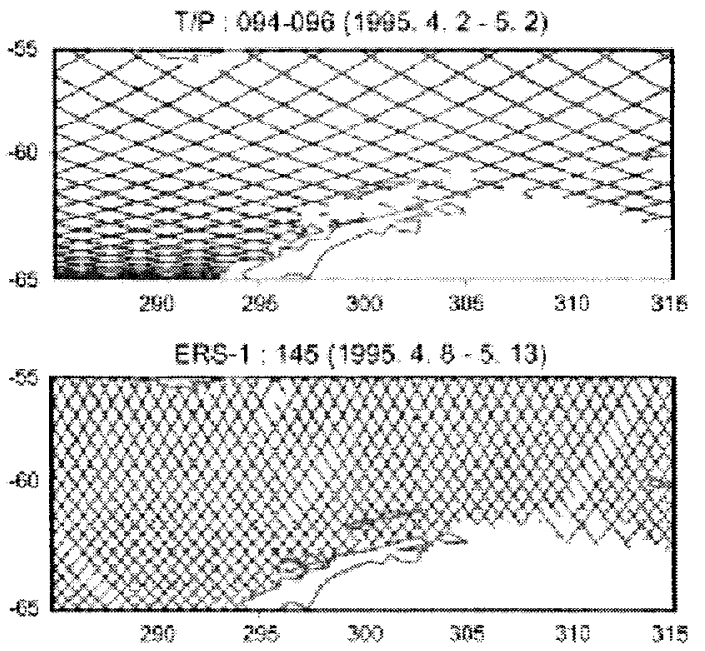

Fig. 8. Comparison of Topex/Poseidon and ERS-1 sea ice distributions. The surface that is not covered with satellite ground tracks denotes sea ice. 
were found in late August and February in the study area, respectively. We also studied the sea ice distribution using ERS-1 data, using the Valid/Invalid flag of the OPR. We mapped the sea ice distribution between March and August of 1995 and also compared with T/P result during the austral autumn, which showed very good correlation with each other.

However, there is a limitation in this approach. It is the size of footprint of a satellite, which is roughly between 2 and $6 \mathrm{~km}$ depending on the roughness of the sea surface. This may be too big to monitor the sharp boundary between ice and water/land. If more other altimeter mission data with dense coverage such as Geosat GM are analyzed together, this limitation can be significantly improved. If we also combine other microwave remote sensing data such as radiometer, and SSM/I, the result will be significantly enhanced.

\section{Acknowledgments}

The T/P MGDR altimeter data were obtained from the NASA/PODAAC at the JPL/CALTEC. This study was supported partially by the Polar Research Program of Korea Ocean Research \& Development Institute.

\section{References}

Benada, R. 1997. Merged GDR(Topex/Poseidon) Generation
$B$ User's Handbook. Physical Oceanography Distributed Active Archive Center, Jet Propulsion Lab., 124 p.

Carsey, F.D., R.G. Barry, and W.F. Weeks. 1992. Chapter 1. Introduction. p.1-7. In: Microwave Remote Sensing of Sea Ice, ed. by F.D. Carsey.

CLS. 1993. Quality Assessment of CERSAT Altimetry OPR Products, OCNT-93.005, CDs.

French Processing and Archiving Facility. 1995. Altimeter and Microwave Radiometer ERS Product User Manual, Ref. C2-MUT-A-01-IF, Vol. 1.2.

Fu, L.L. and A. Cazenave. 2001. Satellite Altimetry and Earth Sciences - A Handbook of Techniques and Applications. International Geophysics Series, Vol. 69, Academic Press, $463 \mathrm{p}$.

Hong, C.-K., S. Hong, J.-S. Hwang, D.C. Lee, and J.W. Kim. 2000. Distribution of altimetry-implied sea ice in the Weddell Sea, Antarctica: Preliminary Results, Proceeding of International Symposium on Remote Sensing, Korea Remote Sensing Society, p. 122-126.

Jeffries, M.O. 1998. Antarctic Sea Ice-Physical Processes, Interactions and Variability. American Geophysical Union, $407 \mathrm{p}$.

Kim, J.W., S. Hong, D.C. Lee, and C.-K. Hong. 2001. Satellite altimetry-implied sea ice in the Weddell Sea, Antarctica, Proceedings of 2001 IEEE International Geoscience and Remote Sensing Society.

Massom, R. 1991. Satellite Remote Sensing of Polar Regions. Lewis Publications, Boca Raton, Florida, 307 p.

Received Mar. 1, 2002 Accepted Sep. 30, 2002 